\title{
Does Trans-Spinal Direct Current Stimulation Alter Phrenic Motoneurons and Respiratory Neuromechanical Outputs in Humans? A Double-Blind, Sham-Controlled, Randomized, Crossover Study
}

\author{
Marie-Cécile Niérat, ${ }^{1,2}$ Thomas Similowski, ${ }^{1,2,3}$ and Jean-Charles Lamy ${ }^{4}$ \\ ${ }^{1}$ Sorbonne Universités, Université Pierre et Marie Curie (UPMC) Univ. Paris 06, UMR_S 1158, Neurophysiologie Respiratoire Expérimentale et Clinique, \\ F-75005 Paris, France, ${ }^{2}$ Institut National de la Santé et de la Recherche Médicale (Inserm), UMR S 1158, Neurophysiologie Respiratoire Expérimentale et \\ Clinique, F-75005 Paris, France, ${ }^{3}$ Assistance Publique-Hôpitaux de Paris, Groupe Hospitalier Pitié-Salpêtrière Charles Foix, Service de Pneumologie et \\ Réanimation Médicale (département R3S), F-75013 Paris, France, and "Inserm U 1127, CNRS UMR 7225, Sorbonne Universités, UPMC Univ. Paris 06, \\ UMR S 1127, Institut du Cerveau et de la Moelle épinière, Centre de Neuro-imagerie de Recherche, F-75013 Paris, France
}

\begin{abstract}
Although compelling evidence has demonstrated considerable neuroplasticity in the respiratory control system, few studies have explored the possibility of altering descending projections to phrenic motoneurons (PMNs) using noninvasive stimulation protocols. The present study was designed to investigate the immediate and long-lasting effects of a single session of transcutaneous spinal direct current stimulation (tsDCS), a promising technique for modulating spinal cord functions, on descending ventilatory commands in healthy humans. Using a double-blind, controlled, randomized, crossover approach, we examined the effects of anodal, cathodal, and sham tsDCS delivered to the C3-C5 level on (1) diaphragm motor-evoked potentials (DiMEPs) elicited by transcranial magnetic stimulation and (2) spontaneous ventilation, as measured by respiratory inductance plethysmography. Both anodal and cathodal tsDCS induced a progressive increase in DiMEP amplitude during stimulation that persisted for at least 15 min after current offset. Interestingly, cathodal, but not anodal, tsDCS induced a persistent increase in tidal volume. In addition, (1) short-interval intracortical inhibition, (2) nonlinear complexity of the tidal volume signal (related to medullary ventilatory command), (3) autonomic function, and (4) compound muscle action potentials evoked by cervical magnetic stimulation were unaffected by tsDCS. This suggests that tsDCS-induced aftereffects did not occur at brainstem or cortical levels and were likely not attributable to direct polarization of cranial nerves or ventral roots. Instead, we argue that tsDCS could induce sustained changes in PMN output. Increased tidal volume after cathodal tsDCS opens up the perspective of harnessing respiratory neuroplasticity as a therapeutic tool for the management of several respiratory disorders.
\end{abstract}

Key words: humans; phrenic motoneurons; plasticity; spinal DC stimulation

\section{Introduction}

Evidence has accumulated over recent years demonstrating that the respiratory rhythm-generating network exhibits potent plasticity (Mitchell and Johnson, 2003; Demoule et al., 2008; DaleNagle et al., 2010; Mitchell and Terada, 2011). For example, hypoxia, learning, training, injury, stress, or pharmacological in-

\footnotetext{
Received March 30, 2014; revised Sept. 1, 2014; accepted Sept. 14, 2014

Author contributions: T.S. and J.-C.L. designed research; M.-C.N. and J.-C.L. performed research; M.-C.N. analyzed data; M.-C.N., T.S., and J.-C.L. wrote the paper.

This work was supported by a "Legs Poix" grant from the Chancellerie de l'Université de Paris (Paris, France); a support grant from the Association pour le Développement et l'Organisation de la Recherche en Pneumologie et sur le Sommeil (Paris, France); and by the French government - Institut Hospitalo-Universitaire - A - Institut du cerveau et de la Moelle épinière (IHU-A-ICM) "Investissement d'avenir" ANR-10-IAlHU-06 program. We thank Christian Straus for suggesting the noise titration approach and Nicolas Wattiez for performing the corresponding analysis; and Anthony Saul, M.B. B.S., professional medical editor, for help with English style and grammar.

The authors declare no competing financial interests.

Correspondence should be addressed to Dr. Jean-Charles Lamy, Groupe Hospitalier Pitié-Salpêtrière, ICM Building, Room 3.028, 47-83, boulevard de I'Hôpital, 75651 Paris Cedex 13, France. E-mail: jeancharles.lamy@gmail.com. DOI:10.1523/JNEUROSCI.1288-14.2014

Copyright $\odot 2014$ the authors $\quad 0270-6474 / 14 / 3414420-10 \$ 15.00 / 0$
}

terventions induce a windup of respiratory activity termed ventilatory long-term facilitation (vLTF), which is expressed as a persistent increase in respiratory motor output that outlasts the stimulation period by several minutes to hours (Mitchell et al., 2001; Mateika and Syed, 2013). This vLTF results from enhanced phrenic motoneuron (PMN) output (Fuller et al., 2000; Johnson and Mitchell, 2013). In humans, noninvasive brain stimulation protocols, such as repetitive transcranial magnetic stimulation (rTMS) or transcranial direct current stimulation (tDCS), can induce long-term respiratory neuroplasticity (Raux et al., 2010; Azabou et al., 2013; Laviolette et al., 2013). Recently, there has been a growing interest in application of DC stimulation over the spinal cord [transcutaneous spinal direct current stimulation (tsDCS)] because of its acceptable safety record, low cost, and potential use in outpatients (Priori et al., 2014). Indeed, in humans, it has been shown that tsDCS can modulate activity in lemniscal (Cogiamanian et al., 2008), extralemniscal (Cogiamanian et al., 2011; Truini et al., 2011), and corticospinal (Lim and Shin, 2011) tracts, 
as well as segmental spinal motor circuits (Winkler et al., 2010; Lamy et al., 2012). Although the mechanisms underlying tsDCS aftereffects are poorly understood at the present time, several studies have suggested that (1) glutamatergic neurotransmission is altered after tsDCS (Ahmed and Wieraszko 2012), leading to the assumption that tsDCS aftereffects are likely to occur via activation of neuronal processes terminating in the spinal cord, which are responsible for expression of long-term potentiation in postsynaptic spinal cord motoneurons; (2) DC polarization could affect the intrinsic properties of the motoneurons (Ahmed, 2011); (3) tsDCS could modulate the spontaneous discharges in ventral roots (Fuortes, 1954; Ahmed, 2011); and (4) tsDCS aftereffects differ according to the direction of the current and the position of the electrodes (Ahmed, 2014; Parazzini et al., 2014).

PMNs, located in C3-C5 cervical spinal segments (Verin et al., 2011), are the site of interactions between various sources of the respiratory motor output (Aminoff and Sears, 1971) and are most likely instrumental to the interplay between bulbospinal and corticospinal respiratory drive that characterizes human respiratory control (Murphy et al., 1990; Davey et al., 1996; Straus et al., 2004; Mehiri et al., 2006). Since persistent changes in synaptic inputs to PMNs have been proposed as a key mechanism underlying vLTF in physiological conditions, we hypothesized that noninvasive stimulation could be used to artificially promote spinal respiratory neuroplasticity. To address this issue, we applied tsDCS at the cervical level according to the protocol developed by Lim and Shin (2011). Using a double-blind, shamcontrolled, randomized, crossover approach, we tested the possibilities of tsDCS to (1) induce long-lasting plastic changes of corticophrenic excitability and (2) determine whether these putative changes would be associated with a modified breathing pattern.

\section{Materials and Methods}

\section{Subjects}

Experiments were performed on 22 healthy participants, naive to DC stimulation protocols, with no history of pulmonary or neuromuscular disease ( 13 females and 9 males; age, $21-45$; mean age \pm SD, $28.26 \pm 6.6$ years). However, not all subjects participated in every experiment. The study was approved by the appropriate legal and ethical authority (CPP Ile de France VI-Pitié-Salpêtrière, Paris, France) and was conducted according to the guidelines of the World Medical Association (Declaration of Helsinki). Written informed consent was obtained from all participants. For each experiment, the subjects were comfortably seated in a reclining chair with their eyes open.

\section{EMG recording}

Surface electromyography (EMG) was recorded from the right hemidiaphragm and, for control purposes, from the biceps brachii (BB) and abductor digiti minimi (ADM) using disposable $\mathrm{Ag} / \mathrm{AgCl}$ electrodes (Kendall). For the diaphragm, one electrode was placed in the eighth intercostal space, between the costochondral junction and the midclavicular line, and the other electrode was placed on the overlying rib at a distance of no more than $2 \mathrm{~cm}$. This montage corresponds to a modified technique validated to minimize the risk of signal contamination by EMG activities from extradiaphragmatic muscles coactivated by TMS (Demoule et al., 2003a). A ground electrode was placed on the iliac spine. As a quality criterion, the mechanical response of the diaphragm to TMS was assessed in terms of the induced changes in abdominal circumference with a piezoelectric belt-mounted transducer attached to an elastic belt placed at the level of the umbilicus (ADinstrument/Pneumotrace II; UFI). As the diaphragm is the only muscle in which contraction increases abdominal circumference, EMG responses to TMS were considered to have a diaphragmatic origin if they were concomitant to such an increase. EMG from the BB and ADM were recorded in a belly-tendon montage. EMG signals were amplified $(\times 1000)$, filtered with a bandpass of $10-$

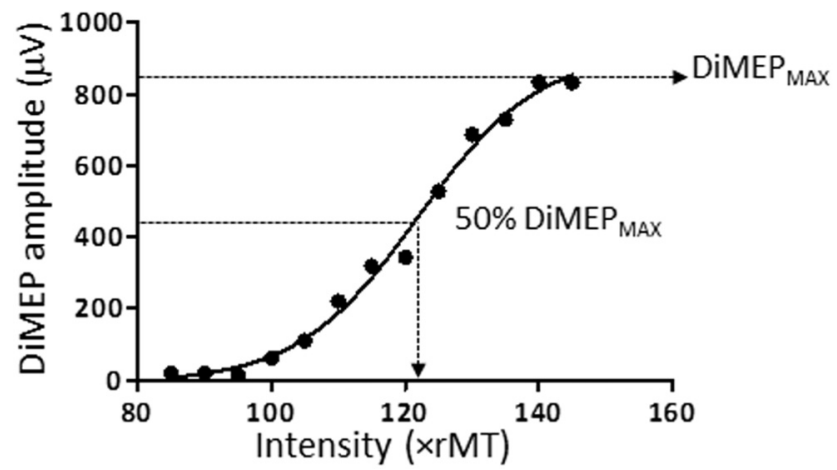

Figure 1. Example of the DiMEP stimulus-response curve obtained in one subject. The curve was fitted using the following three-parameter sigmoid function: $\operatorname{DiMEP}(s)=\frac{\operatorname{DiMEP}_{\text {MAX }}}{1+e \frac{S 50+S}{k}}$, where $S$ is the stimulus intensity, DiMEP $_{\text {MAX }}$ is the maximum MEP evoked in the diaphragm, $k$ the slope of the function, and $S_{50}$ the stimulation intensity required to induce $50 \%$ DiMEP $_{\text {MAX }}$. In all electrophysiological experiments, unconditioned DiMEPs were recorded at $S_{50}$, i.e., the intensity required to induce DiMEPs corresponding to $50 \%$ of DiMEP MAX $_{\text {(see arrow). Complete curves were not recorded in all subjects, but DiMEP }}$ MAX was determined at the beginning of each experiment by increasing the TMS intensity.

$1000 \mathrm{~Hz}$ [1902 isolated amplifier; Cambridge Electronic Design (CED)], digitized at $2 \mathrm{kHz}$ using a Power 1401 data acquisition interface (CED), and stored on a personal computer for off-line analysis (Signal Software version 5.05a; CED).

\section{TMS procedure}

Diaphragm motor-evoked potentials (DiMEPs) were elicited at random (ranging from one to five ventilatory cycles) in a relaxed state, i.e., at the end of tidal expiration using a Magstim Bistim² 200 (Magstim Company) connected to a double-cone coil ( $90 \mathrm{~mm}$; Magstim Company) positioned perpendicular to the scalp near or over the vertex and oriented to deliver and anteroposterior-directed current. The optimal stimulus site was determined as the site at which TMS, at a slightly suprathreshold intensity, consistently induced the largest-amplitude DiMEPs. A neuronavigation system (Visor2; ANT Neuro) was used to ensure reliable and constant placement of the coil throughout the experiment. Resting motor threshold (rMT) was defined to the nearest $1 \%$ stimulator output as the lowest stimulus intensity that elicited motorevoked potentials (MEPs) $>50 \mu \mathrm{V}$ in least 5 of 10 consecutive TMSs (Rossini et al., 1994). The intensity of the stimulus was then set to evoke DiMEPs corresponding to $50 \%$ of maximum DiMEP amplitude (DiMEP $_{\text {MAX }}$; Fig. 1). Short intracortical inhibition (sICI) was evoked using a paired-pulse technique with a subthreshold conditioning stimulus delivered $2 \mathrm{~ms}$ before a suprathreshold test stimulus of TMS, adjusted to evoke DiMEPs corresponding to $50 \%$ of DiMEP MAX $_{\text {(Kujirai et al., }}$ 1993). To avoid any ceiling effect, we first created an intensity curve for sICI by using intensities of $0.8,0.7,0.6$, and $0.5 \times$ rMT (Stinear and Byblow, 2004). During experiments, the intensity of the conditioning stimulus was adjusted in each subject according to the intensity curve at the highest intensity evoking inhibition.

\section{Breathing pattern assessment}

Respiratory pattern was measured using a respiratory inductance plethysmography vest (Visuresp; RBI). The rib cage and abdominal signals related to breathing activity were amplified, filtered, analog-to-digital converted at a $40 \mathrm{~Hz}$ sampling rate (Maclab 16S, Powerlab System; AD Instruments), and stored on a personal computer for subsequent analysis (Chart version 5.2 software; AD Instruments).

\section{Spinal DC stimulation procedure}

tsDCS was delivered by a battery-driven direct current stimulator (Eldith DC stimulator; Neuroconn) connected to a pair of saline-soaked sponge electrodes ( $7 \mathrm{~cm}$ long $\times 5 \mathrm{~cm}$ wide) covered with electrolyte gel. Before positioning the electrodes in a direction longitudinal to the spinal col- 


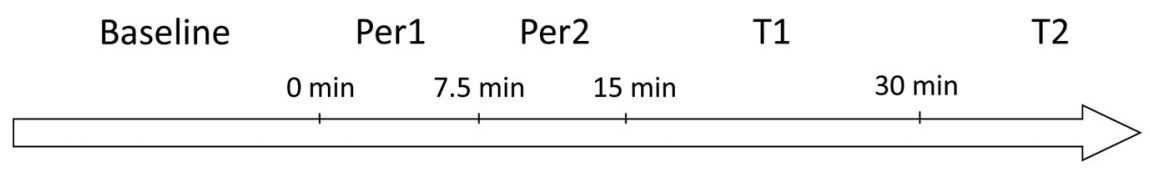

Set 1: effect of tsDCS on electrophysiological parameters

\begin{tabular}{|c|c|c|c|}
\hline DIMEP & DIMEP & DIMEP & DIMEP \\
\hline $\begin{array}{l}\text { rMT } \\
\text { SICI }\end{array}$ & & & $\begin{array}{l}\text { rMT } \\
\text { SICI }\end{array}$ \\
\hline CMS & & & CMS \\
\hline
\end{tabular}

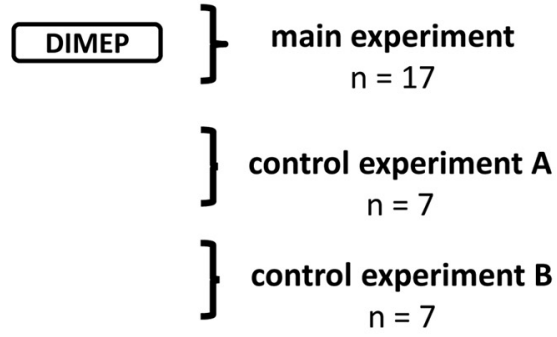

Set 2: effect of tsDCS on spontaneous ventilation

\begin{tabular}{|c|c|c|}
\hline TIDAL BREATHING & TIDAL BREATHING & TIDAL BREATHING \\
\hline & $\begin{array}{l}\text { anodal } \\
\text { cathodal } \\
\text { sham } \\
\text { tsDCS }\end{array}$ & \\
\hline $\begin{array}{c}\text { AUTONOMIC } \\
\text { FUNCTION } \\
\text { (ECG - GSR) }\end{array}$ & $\begin{array}{l}\text { AUTONOMIC } \\
\text { FUNCTION } \\
\text { (ECG - GSR) }\end{array}$ & $\begin{array}{c}\text { AUTONOMIC } \\
\text { FUNCTION } \\
\text { (ECG - GSR) }\end{array}$ \\
\hline
\end{tabular}

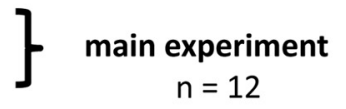

J control experiment C

Figure 2. Experimental setup of the two main experiments and the three control experiments. $n$, Number of subjects included in each experiment; Baseline, before applying tsDCS; Per1, during stimulation from current onset to $7.5 \mathrm{~min}$; Per2, during stimulation from 7.5 to $15 \mathrm{~min} ; \mathrm{T} 1$, immediately after current offset; $\mathrm{T} 2,15 \mathrm{~min}$ after current offset.

umn with rubber bands, the skin was cleaned with an abrasive skin prep and alcohol to lower impedance. One electrode was placed on the midline of the posterior part of the neck to cover cervical spinal segments C3-C5, and the other electrode was placed on the midline of the anterior part of the neck, just below the cervicomental angle (Lim and Shin, 2011). Polarity of stimulation refers to the spinal electrode. The stimulus intensity was set at $2.5 \mathrm{~mA}$ and was applied over a $15 \mathrm{~min}$ period (Cogiamanian et al., 2008; Winkler et al., 2010; Lamy et al., 2012) resulting in a current density of $0.071 \mathrm{~mA} / \mathrm{cm}^{2}$ and a delivered total charge of $64 \mathrm{mC} /$ $\mathrm{cm}^{2}$. The current was ramped up to $2.5 \mathrm{~mA}$ over a $10 \mathrm{~s}$ period and similarly ramped down at the end of stimulation. The sham condition was achieved by delivering a $2.5 \mathrm{~mA}$ current over a 90 s period (Lamy et al., 2012).

\section{Cervical magnetic stimulation procedure}

Compound muscle action potentials (CMAPs) were recorded from the right hemidiaphragm. However, since the origin of CMS-evoked CMAPs in this muscle has been debated [i.e., direct activation of cervical roots as in all other muscles (Chokroverty et al., 1995) or direct activation of the phrenic nerve (Similowski et al., 1997)], we also recorded responses evoked in the BB [i.e., a muscle innervated by part of the same spinal segments (C5-C6) as the diaphragm] and the ADM (i.e., a "control" muscle for which spinal segments $\mathrm{C} 8-\mathrm{T} 1$ are also activated by the lower part of the TMS coil). Cervical magnetic stimulation (CMS) was delivered by a Magstim Bistim ${ }^{2} 200$ (Magstim Company) with a 90-mmdiameter circular coil (Magstim Company). CMS was performed with the hole centering the coil placed over the spinous process of the seventh cervical vertebra (Similowski et al., 1989, 1997) and firmly held against the spine. The coil currents were directed clockwise so that the currents induced in the body were directed from the muscles to the spinal cord in the upper edge of the coil (Matsumoto et al., 2010). Stimulation intensities were increased stepwise from 40 to $100 \%$ of the maximum stimulator output (MSO) with increments of $20 \%$ MSO. Three responses were av- eraged at each intensity. All stimulations were delivered at the endexpiratory phase of the ventilatory cycle.

\section{Autonomic function assessment}

Both galvanic skin response (GSR) and electrocardiogram (ECG) were measured as autonomic markers of physiological arousal. Ag/AgCl GSR electrodes (MLT117F; AD Instruments) were strapped to the distal phalanx of the left index and middle fingers. The signal was acquired with a GSR Amp (AD Instruments). The ECG was recorded simultaneously with three conventional $\mathrm{Ag} / \mathrm{AgCl}$ electrodes. ECG signals were amplified with a Bio Amp (FE132; AD Instruments). Both GSR and ECG signals were conveyed to the PowerLab record unit (AD Instruments), connected to dedicated software for off-line analysis (Chart version 5.2 software; $\mathrm{AD}$ Instruments).

\section{Experimental design}

Two different sets of experiments were conducted (Fig. 2). All experiments were conducted on separate days with minimal inter-session intervals of $3 \mathrm{~d}$ (average, $5 \mathrm{~d}$ ). With the exception of control experiments $\mathrm{B}$ and $\mathrm{C}$, each subject participated in three sessions (anodal, cathodal, and sham). A double-blind approach was used by shielding the stimulator control panel from the view of both the participants and the investigator performing the stimulation (M.-C.N.). The stimulation sequence was randomized for each subject by the unblinded investigator (J.-C.L.). Given that only cathodal tsDCS intervention affected both electrophysiological parameters and spontaneous ventilation (see Results), control experiments B and C were performed exclusively with cathodal tsDCS. The investigators were therefore unblinded for these two control experiments.

Set 1: Effects of tsDCS on electrophysiological parameters. For the main experiment, performed in 17 healthy subjects, $\sim 40$ DiMEPs were recorded at each of the following five time points: before applying tsDCS (baseline), during tsDCS delivery starting immediately after current on- 
set (Per1), during tsDCS delivery starting $7.5 \mathrm{~min}$ after current onset (Per2), immediately after current offset (T1), and 15 min after current offset (T2). For this set of experiments, the intensity of stimulation, expressed as a percentage of MSO, was maintained constant across all time points.

Control experiments A and B were performed in seven subjects who had previously participated in the main experiment. In control experiment A, sICI (obtained by randomly alternating 25 unconditioned and 25 conditioned DiMEPs) and rMT were recorded before applying anodal, cathodal, or sham tsDCS (baseline) and immediately after current offset (T1). Given that both anodal and cathodal tsDCS enhanced DiMEP amplitude and reduced DiMEP threshold (see Results), the intensity of the test stimulus was carefully adjusted to maintain a constant amplitude of the unconditioned DiMEP throughout the experiment. At T1, the intensity of conditioned DiMEP was also adjusted to the same percentage of rMT prerecorded at baseline. In control experiment B, CMS-evoked CMAPs were recorded before applying cathodal tsDCS (baseline) and immediately after current offset (T1).

Set 2: Effects of tsDCS on spontaneous ventilation. For the main experiment, performed in the 12 subjects ( 7 of whom had participated in the main study of set 1), the effects of tsDCS on breathing pattern were investigated. In control experiment $\mathrm{C}$, heart rate variability (rMSSD), calculated from the ECG, and GSR responses were recorded. For both experiments, subjects were instructed to relax, stay quiet, and keep their eyes open, and special care was taken to maintain a silent experimental area. Both breathing pattern (main experiment) and autonomic function assessment (control experiment C) were studied during three $15 \mathrm{~min}$ epochs: before applying tsDCS (baseline), during tsDCS delivery (Per), and immediately after current offset (T1). The first minute of each epoch was discarded from the analysis to allow stabilization of the breathing pattern and of the autonomic function.

\section{Data analysis}

DiMEPs and CMS-evoked CMAPs were included in the analysis when they met the following three criteria: (1) absence of contamination by electrocardiographic complexes; (2) absence of prestimulus EMG activity measured as the root mean square (RMS) amplitude over $100 \mathrm{~ms}$ before stimulation; and (3) concomitant abdominal expansion. The area under the curve (AUC) of DiMEPs and CMS-evoked CMAPs was measured on the rectified EMG responses. DiMEPs and CMS-evoked CMAPs latencies were measured on the nonrectified EMG responses as the time elapsed between the stimulus and the first observable deflection of the EMG signal from baseline. For each subject, DiMEP AUC, latency, and prestimulus EMG were averaged across trials for each time point and normalized to percentage baseline (baseline). For CMS-evoked CMAPs, all responses were normalized to the value obtained at $100 \%$ MSO prerecorded at baseline. sICI was calculated as the ratio of the mean conditioned DiMEPs over the mean unconditioned test DiMEPs.

The following variables were extracted from breathing pattern recordings (set 2, main experiment): tidal volume $\left(V_{\mathrm{T}}\right)$, inspiratory time $\left(T_{\mathrm{i}}\right)$, total cycle time $\left(T_{\mathrm{T}}\right)$, respiratory frequency $(f)$, and derived variable mean inspiratory flow $\left(V_{\mathrm{T}} / T_{\mathrm{i}}\right)$. For each subject, $V_{\mathrm{T}}, T_{\mathrm{i}}, T_{\mathrm{T}}, f$, and $V_{\mathrm{T}} / T_{\mathrm{i}}$ ratio were averaged across trials for each $15 \mathrm{~min}$ epoch and normalized to percentage baseline.

The tidal volume signal derived from the respiratory inductance plethysmography jacket was tested for nonlinear complexity using the noise titration method (Poon and Barahona, 2001; Fiamma et al., 2007). Briefly, this approach consists of fitting the analyzed data with an array of linear and nonlinear models. If the data are best fitted by a nonlinear model (complexity), noise is added to the signal (noise titration) until the resulting signal becomes best fitted by a linear model. The amount of noise required to obtain this result is the "noise limit" (NL): NL $>0$ indicates complexity within the signal; the higher the NL value, the more complex the signal (Wysocki et al., 2006). As ventilatory complexity is considered to originate in the brainstem respiratory pattern generators in animals and humans (Mangin et al., 2008; Straus et al., 2011; Hess et al., 2013), a putative effect of tsDCS at this level would result in NL variations. Tidal volume data were subsampled at $5 \mathrm{~Hz}$ and examined with a custom-written noise titration routine (MathWorks Inc) derived
Table 1. Comparison of the baseline characteristics of DiMEPs across tsDCS conditions

\begin{tabular}{|c|c|c|c|c|c|}
\hline & Anodal & Cathodal & Sham & $F_{(2,50)}$ value & $p$ value \\
\hline$T$ & 2.79 & 42 & $=2.67$ & 1.234 & 305 \\
\hline y (\%MSO) & 58.12 & 59.24 & 58.88 & 0.662 & 0.523 \\
\hline $\mathrm{AUC}(\mu \mathrm{V} \cdot \mathrm{ms})$ & $1.09 \pm$ & 1.51 & 1.23 & 1.198 & 0.315 \\
\hline Latency (ms) & $15.85 \pm 0.29$ & $15.84 \pm 0.32$ & $15.89 \pm 0.29$ & 0.046 & 0.955 \\
\hline Prestimulus RMS EMG & $6.01 \pm 0.25$ & $6.19 \pm 0.20$ & $6.54 \pm 0.18$ & 1.696 & 0.199 \\
\hline
\end{tabular}

Data are mean $\pm S E$. F and $p$ values pertain to one-way repeated-measures ANOVA.

from the original routine of Poon and Barahona (2001) and modified for multiple dimension testing and repeated assessment (Roulin et al., 2011).

Heart rate variability was measured by temporal time-domain analysis. The root mean square of successive R-R interval differences (rMSSD, in milliseconds), which specifically quantifies parasympathetic activities (Stein et al., 2005), was calculated. Real-time variation in skin conductance (GSR), reflecting sympathetic activity (Boucsein et al., 2012), was calculated in microsiemens.

\section{Statistics}

Parametric analyses were used, as all data sets successfully passed the Shapiro-Wilk test for normality and Levene's test for equality of variance. One-way repeated-measures ANOVAs were computed on raw data to test for baseline differences across tsDCS conditions (Table 1). Two-way ANOVAs with INTERVENTION factor (three levels: anodal, cathodal, or sham) and TIME factor (see Results and footnotes to tables for details regarding the number of levels) were first performed to identify differences between tsDCS conditions at different time points for (1) DiMEP AUC and latency (set 1, main experiment); (2) rMT and sICI (control experiment $\mathrm{A})$; and (3) tidal volume $\left(V_{\mathrm{T}}\right)$, inspiratory time $\left(T_{\mathrm{i}}\right)$, total cycle time $\left(T_{\mathrm{t}}\right)$, frequency $(f)$, and $\mathrm{NL}$ (for trials with $\mathrm{NL}>0$; set 2 , main experiment). Subsequent one-way repeated-measures ANOVAs were performed to detect significant changes in the time course within each condition, using the Dunnett's multiple comparison test (sets 1 and 2, main experiments) or paired $t$ test (control experiment A) as post hoc tests. Two-way repeated-measures ANOVAs with INTENSITY factor (four levels: 40, 60, 80, and 100\% MSO) and TIME factor [two levels: before (baseline) and after (T1) applying tsDCS] were computed separately for each muscle (diaphragm, $\mathrm{BB}$, and $\mathrm{ADM}$ ) to assess the effect of cathodal tsDCS on CMS-evoked CMAP AUC and latency, followed by Tukey's HSD post hoc method (control experiment B). One-way repeated-measures ANOVAs were computed to assess the effect of cathodal tsDCS on rMSSD and GSR parameters (control experiment C). In all tests, statistical significance was assumed if $p<0.05$. All calculations were performed using SigmaPlot (Systat Software).

\section{Results}

tsDCS was well tolerated by all subjects, and no adverse effects were encountered. Most participants reported local itching or a slight tingling sensation that resolved after a few seconds. No subject was able to differentiate active conditions from sham stimulation.

\section{Set 1: Effects of tsDCS on electrophysiological parameters Main experiment}

To test for potential baseline bias among tsDCS conditions, oneway repeated-measures ANOVAs were first performed on raw data for each DiMEP parameter (rMT, TMS intensity, AUC, latency, prestimulus RMS EMG). No significant a priori differences between baseline values were detected (Table 1). To test for differences between tsDCS conditions at different time points, two-way repeated-measures ANOVAs were performed for each DiMEP parameter (Table 2) and revealed a significant INTERVENTION $\times$ TIME interaction $\left(F_{(8,128)}=2.102 ; p=\right.$ $0.04)$ for DiMEP AUC. No other significant difference was de- 
Table 2. Results of two-way repeated-measures ANOVA ( $F$ and $p$ values) assessing the effects of the INTERVENTION factor and the TIME factor on the characteristics of DiMEPs

\begin{tabular}{|c|c|c|c|c|c|c|}
\hline & \multicolumn{2}{|c|}{ INTERVENTION } & \multicolumn{2}{|l|}{ TIME } & \multicolumn{2}{|l|}{ INTERACTION } \\
\hline & $F_{(2,32)}$ value & $p$ value & $F_{(4,64)}$ value & $p$ value & $F_{(8,128)}$ value & $p$ value \\
\hline Normalized AUC & 6.193 & 0.005 & 6.423 & $<0.001$ & 2.102 & 0.04 \\
\hline Latency (ms) & 0.462 & 0.634 & 1.392 & 0.247 & 1.612 & 0.127 \\
\hline Prestimulus RMS EMG & 1.093 & 0.347 & 1.500 & 0.213 & 0.377 & 0.931 \\
\hline
\end{tabular}

The INTERVENTION factor consists of three levels: anodal, cathodal, and sham tsDCS. The TIME factor consists of five levels: before applying tsDCS (baseline), during tsDCS delivery starting immediately after current onset (Per1) during tsDCS delivery starting $7.5 \mathrm{~min}$ after current onset (Per2), immediately after current offset (T1), and $15 \mathrm{~min}$ after current offset (T2). Values in bold indicate a statistically significant difference $(p<0.05)$.

tected (Table 2). One-way repeated-measures ANOVAs were then computed to investigate changes from baseline at each time point within each tsDCS condition and showed a significant effect for both anodal $\left(F_{(4,64)}=4.455 ; p<0.004\right)$ and cathodal $\left(F_{(4,64)}=5.679 ; p<0.001\right)$ conditions, but not for sham intervention $\left(F_{(4,64)}=0.952 ; p=0.44\right)$. Dunnett's post hoc tests showed that both anodal and cathodal tsDCS induced a progressive increase in DiMEP AUC over time that persisted for at least 15-20 min after current offset (Fig. 3).

\section{Control experiment $A$}

To gain knowledge about tsDCS-induced corticophrenic plasticity, we determined both rMT and sICI before (baseline) and after (T1) anodal, cathodal, or sham tsDCS. No a priori differences between baseline values were detected for either rMT $\left(F_{(2,20)}=0.51 ; p=0.61\right)$ or $\operatorname{sICI}\left(F_{(2,20)}=3.136 ; p=0.08\right)$. Two-way repeated-measures ANOVAs revealed a significant INTERVENTION $\times$ TIME interaction for $\operatorname{rMT}\left(F_{(2,41)}=4.453\right.$; $p<0.04$; Table 3). Post hoc paired $t$ tests showed that rMT decreased significantly after both anodal (baseline, $49 \pm 0.03 \%$ MSO; T1, $46 \pm 0.03 \%$ MSO; $p<0.009$ ) and cathodal (baseline, $49 \pm 0.03 \% \mathrm{MSO} ; \mathrm{T} 1,45 \pm 0.02 \% \mathrm{MSO} ; p<0.006)$ stimulations but remained unchanged after sham intervention (baseline, $50 \pm$ $0.03 \% \mathrm{MSO} ; \mathrm{T} 1,49 \pm 0.03 \% \mathrm{MSO} ; p=0.08)$. In contrast, tsDCS failed to modulate $\operatorname{sICI}\left(F_{(2,41)}=0.224 ; p=0.8\right.$; Table 3$)$.

\section{Control experiment $B$}

CMS-evoked CMAPs were recorded in diaphragm, BB, and ADM muscles before (baseline) and after (T1) cathodal tsDCS. For each muscle, two-way repeated-measures ANOVAs showed a significant effect of INTENSITY factor with no effect of TIME factor or INTENSITY $\times$ TIME interaction for either AUC or latency of CMAPs (see Table 4 for details). In accordance with the literature (Ugawa et al., 1989; Schmid et al., 1990; Similowski et al., 1997; Matsumoto et al., 2013), post hoc Tukey's HSD tests indicated that the higher the intensity of stimulation, the larger the AUC of the CMAPs and the shorter its latency (data not shown).

\section{Set 2: Effects of tsDCS on spontaneous ventilation}

Main experiment

One-way repeated-measures ANOVAs failed to detect baseline differences across tsDCS sessions for tidal volume $\left(V_{\mathrm{T}} ; F_{(2,35)}=\right.$ $1.29 ; p=0.294)$, inspiratory time $\left(T_{\mathrm{i}} ; F_{(2,35)}=0.442 ; p=0.648\right)$, total cycle time $\left(T_{\mathrm{t}} ; F_{(2,35)}=0.492 ; p=0.618\right)$, frequency $(f ;$ $\left.F_{(2,35)}=0.654 ; p=0.530\right)$, and noise limit $\left(F_{(2,35)}=0.372 ; p=\right.$ $0.695)$. To test for differences between tsDCS conditions at different time points, two-way repeated-measures ANOVAs were computed for each respiratory parameter (Table 5) and revealed a significant INTERVENTION $\times$ TIME interaction $\left(F_{(4,107)}=\right.$ $2.902 ; p<0.04)$ for tidal volume $\left(V_{\mathrm{T}}\right)$. No other significant dif- ference was detected (Table 5). Subsequent one-way repeatedmeasures ANOVAs were then computed to investigate changes in $V_{\mathrm{T}}$ from baseline at each time point in each tsDCS condition and showed a significant effect for cathodal $\left(F_{(2,35)}=2.902 ; p<0.05\right)$, but not for anodal $\left(F_{(2,35)}=0.986 ; p=0.389\right)$, stimulation or sham intervention $\left(F_{(2,35)}=1.336 ; p=0.283\right)$. Dunnett's post hoc tests showed that cathodal tsDCS induced a progressive increase in $V_{\mathrm{T}}$ over time that persisted for at least $15 \mathrm{~min}$ after current offset (Fig. 4).

The NL value was $>0$ in 32 of 36 trials (i.e., 12 subjects, three time points). Two-way repeated-measures ANOVA showed that ventilatory complexity remained unchanged across tsDCS conditions $\left(F_{(4,80)}=0.506 ; p=0.732\right.$; Table 5$)$.

Control experiment $C$

ECG and GSR were recorded before (baseline), during (Per), and after (T1) cathodal tsDCS. One-way repeated-measures ANOVAs failed to detect any significant changes for either rMSSD $\left(F_{(2,20)}=2.715 ; p=0.107\right)$ or $\operatorname{GSR}\left(F_{(2,20)}=2.733 ; p=0.113\right)$, suggesting that autonomic function was not affected by the intervention.

\section{Discussion}

The present study provides first-time evidence that tsDCS applied over C3-C5 spinal segments is able to induce (1) a persistent increase in the excitability of the corticophrenic pathway, regardless of the polarity used, that outlasts the stimulation period by at least 15-20 min and (2) an increase in respiratory neuromechanical throughput (i.e., tidal volume), which was specific to the cathodal condition.

Few animal studies (Fuortes, 1954; Ahmed, 2014) and a computational approach applied to realistic human models (Parazzini et al., 2014) suggest that thoracic tsDCS can have significant effects on axonal excitability. To test a putative effect of DC polarization on ventral roots, we recorded a stimulus-response curve of CMAPs evoked by CMS in the diaphragm, BB, and ADM before and after cathodal tsDCS. Regardless of the muscle considered, neither the latency nor the AUC of CMAPs was affected by the intervention, suggesting that cathodal tsDCS aftereffects did not result from direct polarization of the cervical ventral roots. Because of the anteroposterior montage used in this study, another possibility is that tsDCS may have induced changes in autonomic function, such as vagus nerve or sympathetic ganglions, that would have direct or indirect effects on respiratory output. Cathodal tsDCS failed to affect sympathetic/parasympathetic activities. Together, these results provide evidence that tsDCS aftereffects are likely not caused by direct polarization of autonomic or somatic nerves. However, unknown changes on structures located beneath the electrodes cannot be excluded.

tsDCS may have interfered with cortical excitability, as tsDCS applied to the thoracic level modulated the cervicomedullary P30 component of the posterior tibial nerve somatosensory-evoked potential (Cogiamanian et al., 2008) and attenuated the spinal processing of nociceptive inputs (Truini et al., 2011), suggesting that tsDCS influences conduction along ascending (lemniscal/ spinothalamic) tracts. To test this hypothesis, we measured sICI, a common method used to investigate changes in $\mathrm{GABA}_{\mathrm{A}}$ intracortical synapses in the motor cortex (Rothwell et al., 2009), in the diaphragm (Demoule et al., 2003b; Sharshar et al., 2004). In our few subjects, sICI was unchanged by tsDCS, suggesting that reduced $\mathrm{GABA}_{\mathrm{A}}$-mediated intracortical inhibition is not responsible for enhanced DiMEPs after tsDCS. However, as TMS evokes multiple corticospinal volleys (I-waves) and as sICI has a greater 

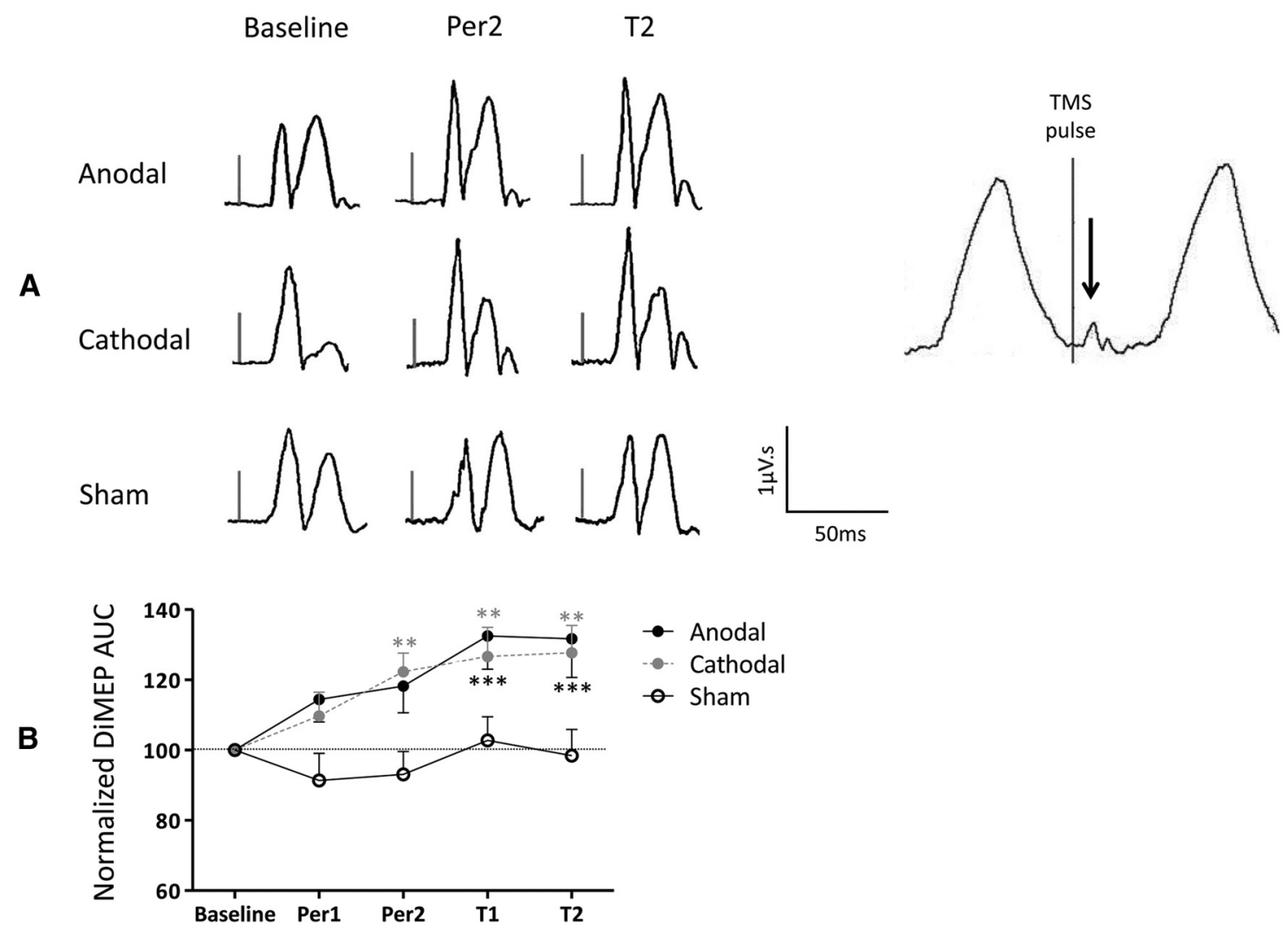

Figure 3. Effects of tsDCS interventions on the DiMEP AUC. A, Examples of rectified waveforms of DiMEP in one representative subject recorded before, during (Per2), and after (T2) delivery of anodal, cathodal, and sham tsDCS. Each trace represents the average of $\sim 40$ DiMEPs. Note the progressive increase in DiMEP AUC in active tsDCS conditions. The diagram on the right, obtained in the same subject, illustrates increased abdominal circumference (see arrow) after one transcranial magnetic stimulation pulse supporting the diaphragmatic origin of the motor-evoked potentials recorded. $\boldsymbol{B}$, Group results illustrating mean changes in the relative DiMEP AUC after anodal (black circles, continuous line), cathodal (gray circles, dashed gray line), and sham (open circles, continuous line) cervical tsDCS with respect to baseline AUC (black dashed line). Per1, During stimulation from current onset to 7.5 min; Per2, during stimulation from 7.5 to 15 min; $\mathrm{T} 1$, immediately after current offset; T2, 15 min after current offset. Error bars denote SEM (17 subjects). Asterisks indicate significant increases in DiMEPs compared with baseline ${ }^{* *} p<0.01 ;{ }^{* * *} p<0.001$, Dunnett's multiple comparison post hoc tests).

Table 3. Results of two-way repeated-measures ANOVA ( $F$ and $p$ values) assessing the effects of the INTERVENTION factor and the TIME factor on SICI and rMT

\begin{tabular}{|c|c|c|c|c|c|c|}
\hline & \multicolumn{2}{|c|}{ INTERVENTION } & \multicolumn{2}{|l|}{ TIME } & \multicolumn{2}{|l|}{ INTERACTION } \\
\hline & $F_{(2,12)}$ value & $p$ value & $F_{(1,6)}$ value & $p$ value & $F_{(2,41)}$ value & $p$ value \\
\hline sICl & 1.265 & 0.317 & 2.491 & 0.166 & 0.224 & 0.803 \\
\hline rMT (\%MSO) & 1.859 & 0.198 & 26.708 & 0.002 & 4.453 & 0.036 \\
\hline
\end{tabular}

The INTERVENTION factor consists of three levels: anodal, cathodal, and sham tsDCS. The TIME factor consists of two levels: before applying tsDCS (baseline) and immediately after current offset (T1). Values in bold indicate a statistically significant difference $(p<0.05)$.

effect on later I-waves than on early ones (Di Lazzaro et al., 1998), we cannot exclude the possibility that tsDCS may preferentially affect early volleys or impact on other intracortical circuits, such as glutamatergic or $\mathrm{GABA}_{\mathrm{B}}$ ergic connections that were not tested in this study.

The fact that tsDCS-related plastic changes in corticophrenic excitability gradually increased over the course of the intervention and outlasted the stimulation period by at least 15-20 min suggests complex synaptic changes rather than a simple membrane-polarizing effect (Cooke and Bliss, 2006; Stagg and Nitsche, 2011). DC stimulation has mainly been investigated using a transcranial approach. Long-lasting effects after brain polarization involve modulation of both glutamatergic and GABAergic synapses and changes in NMDA ionotropic receptor efficacy (Liebetanz et al., 2002; Nitsche et al., 2003) resulting in increased intracellular $\mathrm{Ca}^{2+}$ in the postsynaptic neuron. For these reasons, DC stimulation-induced aftereffects are thought to arise from synaptic changes via long-term potentiation-/ depression-like processes as well as nonsynaptic mechanisms involving changes in neural membrane function (Ardolino et al., 2005). In the light of our results and based on our current understanding of tsDCS mechanisms (Priori et al., 2014), it is conceivable that the mechanisms underlying enhanced DiMEPs after tsDCS could also involve changes in neurotransmission, which would be in line with the fact that (1) glutamate drives the pathway to PMNs during inspiration (McCrimmon et al., 1989; Chitravanshi and Sapru, 1996) and modulates synaptic strength in the short and long term via NMDA receptors (Rekling et al., 2000; McGuire et al., 2008); (2) GABA is intimately involved in respiratory motor control, as $\mathrm{PMN}$ s are inhibited by $\mathrm{GABA}_{\mathrm{A}}$ receptors during the expiratory phase of respiration (Fedorko et al., 1983; Merrill and Fedorko, 1984); and, (3) PMN NMDA receptors also contribute to excitatory neurotransmission (Chitravanshi and Sapru, 1996) and are implicated in many models of plasticity including phrenic LTF (Golder, 2009). This idea is also supported by recent arguments from animal studies: (1) both anodal and cathodal tsDCS increased glutamate analog D-2,3- ${ }^{3} \mathrm{H}$-aspartic acid release in vitro (Ahmed and Wieraszko, 2012), and (2) it has been proposed that cathodal tsDCS may act by directly inhibiting the spinal GABAergic system or by exerting overexcitation of postsynaptic neurons (Ahmed, 2013) likely through increased glutamate release (Ahmed and Wieraszko, 2012). The fact that 
Table 4. Results of two-way repeated-measures ANOVA ( $F$ and $p$ values) assessing the effects of the INTENSITY factor and the TIME factor for both the AUC and the latency of compound muscle action potentials evoked by cervical magnetic stimulation

\begin{tabular}{|c|c|c|c|c|c|c|}
\hline & \multicolumn{2}{|c|}{ INTERVENTION } & \multicolumn{2}{|l|}{ TIME } & \multicolumn{2}{|l|}{ INTERACTION } \\
\hline & $F_{(3,18)}$ value & $p$ value & $F_{(1,6)}$ value & $p$ value & $F_{(3,55)}$ value & $p$ value \\
\hline \multicolumn{7}{|l|}{$\operatorname{AUC}(\mu \mathrm{V} \cdot \mathrm{ms})$} \\
\hline Diaphragm & 78.906 & $<0.001$ & 0.665 & 0.446 & 0.140 & 0.934 \\
\hline$B B^{\prime}$ & 49.812 & $<0.001$ & 0.905 & 0.378 & 2.653 & 0.080 \\
\hline ADM & 110.056 & $<0.001$ & 0.0336 & 0.861 & 0.335 & 0.800 \\
\hline \multicolumn{7}{|l|}{ Latency (ms) } \\
\hline Diaphragm & 16.066 & $<0.001$ & $5.00 \mathrm{E}-27$ & 1.000 & 1.193 & 0.340 \\
\hline$B B$ & 14.152 & $<0.001$ & 1.333 & 0.292 & 1.192 & 0.341 \\
\hline ADM & 6.230 & 0.004 & 0.538 & 0.491 & 2.558 & 0.087 \\
\hline
\end{tabular}

The INTENSITY factor consists of four levels: 40,60,80, and 100\% MSO). The TIME factor consists of two levels: before applying cathodal tsDCS (baseline) and after current offset (T1). Values in bold indicate a statistically significant difference $(p<0.05)$.

Table 5. Results of two-way repeated-measures ANOVA ( $F$ and $p$ values) assessing the effects of the INTERVENTION factor and the TIME factor for breathing pattern descriptors

\begin{tabular}{|c|c|c|c|c|c|c|}
\hline & \multicolumn{2}{|l|}{ INTERVENTION } & \multicolumn{2}{|l|}{ TIME } & \multicolumn{2}{|l|}{ INTERACTION } \\
\hline & Fvalue & $p$ value & $F$ value & $p$ value & Fvalue & $p$ value \\
\hline Normalized tidal volume $V_{T}$ & $F_{(2,22)}=3.48$ & 0.049 & $F_{(2,22)}=1.021$ & 0.377 & $F_{(4,107)}=2.902$ & 0.032 \\
\hline Inspiratory time $T_{\mathrm{i}}(\mathrm{s})$ & $F_{(2,22)}=0.661$ & 0.526 & $F_{(2,22)}^{(1,22)}=2.593$ & 0.097 & $F_{(4,107)}=1.216$ & 0.318 \\
\hline Total respiratory cycle time $T_{\mathrm{t}}(\mathrm{s})$ & $F_{(2,22)}^{(2,2)}=0.874$ & 0.431 & $F_{(2,22)}=2.519$ & 0.103 & $F_{(4,107)}^{(1,107)}=0.966$ & 0.436 \\
\hline Frequency $f$ & $F_{(2,22)}^{(2,2)}=1.820$ & 0.186 & $F_{(2,22)}=2.926$ & 0.075 & $F_{(4,107)}=0.729$ & 0.577 \\
\hline Normalized $V_{\mathrm{T}} / T_{\mathrm{i}}$ & $F_{(2,22)}=0.413$ & 0.666 & $F_{(2,22)}^{(2,22)}=1.039$ & 0.370 & $F_{(4,107)}=0.566$ & 0.688 \\
\hline Noise limit & $F_{(2,16)}^{(2,2)}=0.260$ & 0.774 & $F_{(2,16)}=0.282$ & 0.758 & $F_{(4,80)}=0.506$ & 0.732 \\
\hline
\end{tabular}

The INTERVENTION factor consists of three levels: anodal, cathodal, and sham tsDCS. The TIME factor consists of three levels: before applying tsDCS (baseline), during tsDCS application (Per), and after current offset (T1). Values in bold indicate a statistically significant difference $(p<0.05)$.

A

sham

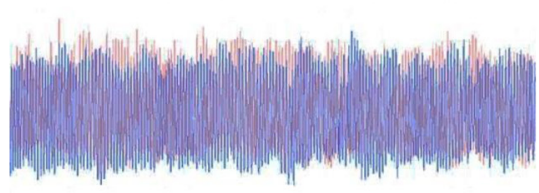

cathodal

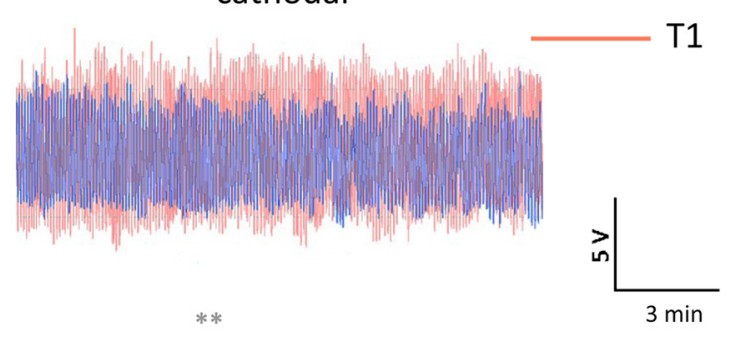

Baseline

1
B

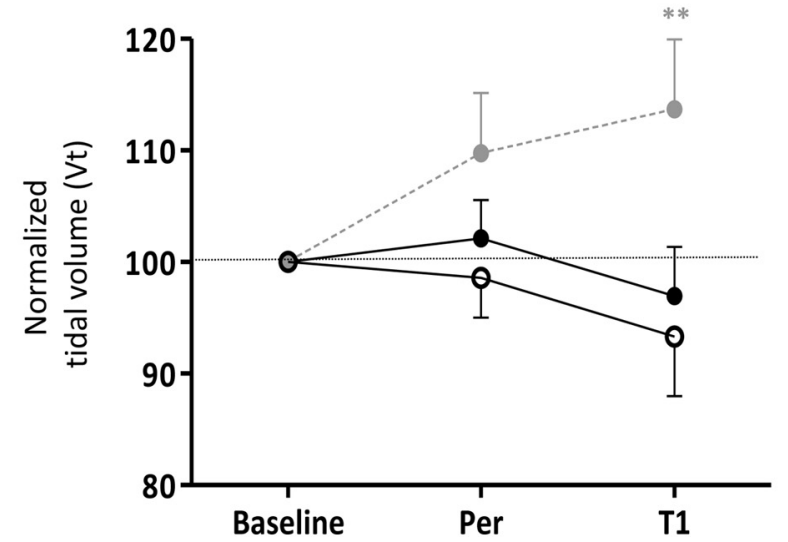

$\rightarrow$ Anodal

- Cathodal

- Sham

Figure 4. Effects of tsDCS interventions on tidal volume. $A$, Examples of tidal volume recorded 15 min before (blue traces, T0) and 15 min after (red traces, $T 1$ ) sham (left) and cathodal (right) tsDCS in one representative subject. Tidal volume increased after cathodal tsDCS but not in the sham condition. $\boldsymbol{B}$, Mean changes in tidal volume $\left(V_{T}\right.$, after normalization to baseline) after anodal (black circles, continuous line), cathodal (gray circles, dashed gray line), and sham (open circles, continuous line) cervical tsDCS with respect to baseline $V_{T}$ (black dashed line). Baseline, Before applying tsDCS; Per, during tsDCS application; T1, after current offset. Error bars denote SEM (12 subjects). Asterisk indicates a significant increase in $V_{\mathrm{T}}$ compared with baseline ${ }^{* *} p<0.01$, Dunnett's multiple comparison post hoc tests).

tsDCS can modulate firing rate, pattern, and amplitude of the spontaneous activity of the tibial nerve in mice (Ahmed, 2011) is also compatible with the idea that cervical tsDCS could affect the intrinsic properties of PMNs. These changes may involve a shift in the motoneuron firing threshold, changes in afterhyperpolarization amplitude, changes in synaptic contact on motoneurons, or changes in the firing threshold of the axon (Wolpaw and Carp, 2006).

The fact that DiMEPs were enhanced regardless of the polarity of stimulation, whereas only cathodal tsDCS was associated with increased neuromechanical throughput (i.e., increased tidal vol- 
ume), also supports the view that tsDCS may act at the PMN level. Indeed, PMNs can be classified according to their bursting patterns (Kong and Berger, 1986; Lee et al., 2009): early-inspiratory (early-I) PMNs begin to discharge during the initial part of inspiration, whereas late-inspiratory (late-I) PMNs begin bursting after $\sim 10-40 \%$ of the inspiratory period has elapsed (Lee and Fuller, 2011). Burst onset differences between PMN subtypes are likely to reflect intrinsic motoneuron properties (Berger, 1979): early-I PMNs are high-resistant small cells, whereas late-I PMNs are low-resistant large cells. Thus, during spontaneous ventilation, in which respiratory-related discharges of PMNs are primarily driven by bulbospinal inputs, early-I PMNs would be recruited before late-I PMNs according to the size principle of motoneuron recruitment established by Henneman et al. (1965). Enhanced tidal volume after cathodal tsDCS is in line with previous reports demonstrating the potential of cathodal tsDCS stimulation to specifically facilitate spinal excitability (Alanis, 1953; Aguilar et al., 2011; Ahmed, 2011). It is also consistent with recent data obtained in both animals and humans showing the potential of cathodal polarization to specifically improve the recruitment of larger motor units (Ahmed and Wieraszko, 2012; Bocci et al., 2014). Similarly, as a tentative view, we hypothesize that cathodal tsDCS could facilitate spatiotemporal recruitment of late-I PMNs, which in turn would result in enhanced tidal volume. Of note, the excitability of PMNs differed markedly between our two main experiments, as PMNs were mainly active during the inspiratory phase of ventilation (Saboiskyet al., 2007) and DiMEPs were evoked at the end of tidal expiration i.e., when PMNs were not activated or were even inhibited by brainstem inputs (Duffin et al., 2000). Together with the fact that DiMEPs were enhanced after both anodal and cathodal tsDCS, our findings concerning tidal volume could suggest that tsDCS is more effective to induce depolarization of PMNs when they are in a resting steady state (or hyperpolarized) than when the PMN pool is already depolarized by bulbospinal inputs.

Finally, the fact that tidal volume increased after cathodal tsDCS with no change in inspiratory time also argues in favor of a spinal mechanism, as lung ventilation in humans stems from the rhythmic activity of brainstem central pattern generators governing respiratory muscle timing and contraction. Most physiological circumstances leading to increased ventilation are associated with a more intense central drive to breathe and a prolonged inspiratory time. Although oscillatory in nature, tidal ventilation exhibits breath-by-breath variability (Bendixen et al., 1964) and features chaos-like mathematical complexity (Wysocki et al., 2006). As a result, ventilation and the corresponding neural activity can be described by nonlinear indicators (Del Negro et al., 2002; Schmidt et al., 2010). Both breathing complexity, as assessed by the noise titration approach, and breathing frequency, which depends on the activity of brainstem respiratory pattern generators, were unaffected by tsDCS interventions. Consequently, it is unlikely that tsDCS-induced aftereffects are attributable to changes in brainstem excitability. Our observation of increased tidal volume with no obvious changes in brainstem excitability therefore strongly argues in favor of facilitated throughput at the PMN level. Accordingly, hypoxia-induced short-term potentiation of respiratory motor output in rats is manifested by increased PMN discharge patterns with no changes in central ventilatory drive or inspiratory time (Lee et al., 2009). Similarly, in healthy subjects during sleep, hypoxia-induced vLTF is manifested by enhanced tidal volume with no change in respiratory frequency (i.e., brainstem activity; Syed et al., 2013). Overall, our results may be explained by enhanced spinal output, i.e., if PMNs receive the same descending input after cathodal tsDCS but transmit more of this input to inspiratory muscles.

Although the exact mechanisms underlying our findings still need to be identified and the current flow through cervical structures needs to be more accurately described (Toshev et al., 2014), a long-lasting increase in tidal volume after cathodal tsDCS is of particular interest, as this finding paves the way for therapeutic studies evaluating tsDCS as a tool to increase ventilation in patients suffering from various neural respiratory disorders.

\section{References}

Aguilar J, Pulecchi F, Dilena R, Oliviero A, Priori A, Foffani G (2011) Spinal direct current stimulation modulates the activity of gracile nucleus and primary somatosensory cortex in anaesthetized rats. J Physiol 589:49814996. CrossRef Medline

Ahmed Z (2011) Trans-spinal direct current stimulation modulates motor cortex-induced muscle contraction in mice. J Appl Physiol 110:14141424. CrossRef Medline

Ahmed Z (2013) Effects of cathodal trans-spinal direct current stimulation on mouse spinal network and complex multijoint movements. J Neurosci 33:14949-14957. CrossRef Medline

Ahmed Z (2014) Trans-spinal direct current stimulation alters muscle tone in mice with and without spinal cord injury with spasticity. J Neurosci 34:1701-1709. CrossRef Medline

Ahmed Z, Wieraszko A (2012) Trans-spinal direct current enhances corticospinal output and stimulation-evoked release of glutamate analog, D-2,3-H-3-aspartic acid. J Appl Physiol 112:1576-1592. CrossRef Medline

Alanis J (1953) Effects of direct current on motor neurones. J Physiol 120: 569-578. Medline

Aminoff MJ, Sears TA (1971) Spinal integration of segmental, cortical and breathing inputs to thoracic respiratory motoneurones. J Physiol 215: 557-575. Medline

Ardolino G, Bossi B, Barbieri S, Priori A (2005) Non-synaptic mechanisms underlie the after-effects of cathodal transcutaneous direct current stimulation of the human brain. J Physiol 568:653-663. CrossRef Medline

Azabou E, Roche N, Sharshar T, Bussel B, Lofaso F, Petitjean M (2013) Transcranial direct-current stimulation reduced the excitability of diaphragmatic corticospinal pathways whatever the polarity used. Respir Physiol Neurobiol 189:183-187. CrossRef Medline

Bendixen HH, Smith GM, Mead J (1964) Pattern of ventilation in young adults. J Appl Physiol 19:195-198. Medline

Berger AJ (1979) Phrenic moto-neurons in the cat: subpopulations and nature of respiratory drive potentials. J Neurophysiol 42:76-90. Medline

Bocci T, Vannini B, Torzini A, Mazzatenta A, Vergari M, Cogiamanian F, Priori A, Sartucci F (2014) Cathodal transcutaneous spinal direct current stimulation (tsDCS) improves motor unit recruitment in healthy subjects. Neurosci Lett 578:75-79. CrossRef Medline

Boucsein W, Fowles DC, Grimnes S, Ben-Shakhar G,Roth WT, Dawson ME, Filion DL (2012) Publication recommendations for electrodermal measurements. Psychophysiology 49:1017-1034. CrossRef Medline

Chitravanshi VC, Sapru HN (1996) NMDA as well as non-NMDA receptors mediate the neurotransmission of inspiratory drive to phrenic motoneurons in the adult rat. Brain Res 715:104-112. CrossRef Medline

Chokroverty S, Shah S, Chokroverty M, Deutsch A, Belsh J (1995) Percutaneous magnetic coil stimulation of the phrenic nerve roots and trunk. Electroencephalogr Clin Neurophysiol 97:369-374. CrossRef Medline

Cogiamanian F, Vergari M, Pulecchi F, Marceglia S, Priori A (2008) Effect of spinal transcutaneous direct current stimulation on somatosensory evoked potentials in humans. Clin Neurophysiol 119:2636-2640. CrossRef Medline

Cogiamanian F, Vergari M, Schiaffi E, Marceglia S, Ardolino G, Barbieri S, Priori A (2011) Transcutaneous spinal cord direct current stimulation inhibits the lower limb nociceptive flexion reflex in human beings. Pain 152:370-375. CrossRef Medline

Cooke SF, Bliss TV (2006) Plasticity in the human central nervous system. Brain 129:1659-1673. CrossRef Medline

Dale-Nagle EA, Hoffman MS, MacFarlane PM, Satriotomo L, Lovett-Barr MR, Vinit S, Mitchell GS (2010) Spinal plasticity following intermittent hypoxia: implications for spinal injury. Ann N Y Acad Sci 1198:252-259. CrossRef Medline 
Davey NJ, Murphy K, Maskill DW, Guz A, Ellaway PH (1996) Site of facilitation of diaphragm EMG to corticospinal stimulation during inspiration. Respir Physiol 106:127-135. CrossRef Medline

Del Negro CA, Morgado-Valle C, Feldman JL (2002) Respiratory rhythm: an emergent network property? Neuron 34:821-830. CrossRef Medline

Demoule A, Verin E, Le Locher C, Derenne JP, Similowski T (2003a) Validation of surface recordings of the diaphragm response to transcranial magnetic stimulation in humans. J Appl Physiol 94:453-461. CrossRef Medline

Demoule A, Verin E, Ross E, Moxham J, Derenne JP, Polkey MI, Similowski $\mathrm{T}$ (2003b) Intracortical inhibition and facilitation of the response of the diaphragm to transcranial magnetic stimulation. J Clin Neurophysiol 20: 59-64. CrossRef Medline

Demoule A, Verin E, Montcel ST, Similowski T (2008) Short-term trainingdependent plasticity of the corticospinal diaphragm control in normal humans. Respir Physiol Neurobiol 160:172-180. CrossRef Medline

Di Lazzaro V, Oliviero A, Profice P, Saturno E, Pilato F, Insola A, Mazzone P, Tonali P, Rothwell JC (1998) Comparison of descending volleys evoked by transcranial magnetic and electric stimulation in conscious humans. Electroencephalogr Clin Neurophysiol 109:397-401. CrossRef Medline

Duffin J, Tian GF, Peever JH (2000) Functional synaptic connections among respiratory neurons. Respir Physiol 122:237-246. CrossRef Medline

Fedorko L, Merrill EG, Lipski J (1983) Two descending medullary inspiratory pathways to phrenic motoneurones. Neurosci Lett 43:285-291. CrossRef Medline

Fiamma MN, Samara Z, Baconnier P, Similowski T, Straus C (2007) Respiratory inductive plethysmography to assess respiratory variability and complexity in humans. Respir Physiol Neurobiol 156:234-239. CrossRef Medline

Fuller DD, Bach KB, Baker TL, Kinkead R, Mitchell GS (2000) Long term facilitation of phrenic motor output. Respir Physiol 121:135-146. CrossRef Medline

Fuortes MG (1954) Direct current stimulation of motoneurones. J Physiol 126:494-506. Medline

Golder FJ (2009) Spinal NMDA receptor activation is necessary for de novo, but not the maintenance of, A2a receptor-mediated phrenic motor facilitation. J Appl Physiol 107:217-223. CrossRef Medline

Henneman E, Somjen G, Carpente DO (1965) Functional significance of cell size in spinal motoneurons. J Neurophysiol 28:560-580. Medline

Hess A, Yu L, Klein I, De Mazancourt M, Jebrak G, Mal H, Brugière O, Fournier M, Courbage M, Dauriat G, Schouman-Clayes E, Clerici C, Mangin L (2013) Neural mechanisms underlying breathing complexity. PLoS One 8:e75740. CrossRef Medline

Johnson RA, Mitchell GS (2013) Common mechanisms of compensatory respiratory plasticity in spinal neurological disorders. Respir Physiol Neurobiol 189:419-428. CrossRef Medline

Kong FJ, Berger AJ (1986) Firing properties and hypercapnic responses of single phrenic motor axons in the rat. J Appl Physiol 61:1999-2004. Medline

Kujirai T, Caramia MD, Rothwell JC, Day BL, Thompson PD, Ferbert A, Wroe S, Asselman P, Marsden CD (1993) Corticocortical inhibition in human motor cortex. J Physiol 471:501-519. Medline

Lamy JC, Ho C, Badel A, Arrigo RT, Boakye M (2012) Modulation of soleus H reflex by spinal DC stimulation in humans. J Neurophysiol 108:906914. CrossRef Medline

Laviolette L, Niérat MC, Hudson AL, Raux M, Allard E, Similowski T (2013) The supplementary motor area exerts a tonic excitatory influence on corticospinal projections to phrenic motoneurons in awake humans. PLoS One 8:e62258. CrossRef Medline

Lee KZ, Fuller DD (2011) Neural control of phrenic motoneuron discharge. Respir Physiol Neurobiol 179:71-79. CrossRef Medline

Lee KZ, Reier PJ, Fuller DD (2009) Phrenic motoneuron discharge patterns during hypoxia-induced short-term potentiation in rats. J Neurophysiol 102:2184-2193. CrossRef Medline

Liebetanz D, Nitsche MA, Tergau F, Paulus W (2002) Pharmacological approach to the mechanisms of transcranial DC-stimulation-induced aftereffects of human motor cortex excitability. Brain 125:2238-2247. CrossRef Medline

Lim CY, Shin HI (2011) Noninvasive DC stimulation on neck changes MEP. Neuroreport 22:819-823. CrossRef Medline

Mangin L, Fiamma MN, Straus C, Derenne JP, Zelter M, Clerici C, Similowski
T (2008) Source of human ventilatory chaos: lessons from switching controlled mechanical ventilation to inspiratory pressure support in critically ill patients. Respir Physiol Neurobiol 161:189-196. CrossRef Medline

Mateika JH, Syed Z (2013) Intermittent hypoxia, respiratory plasticity and sleep apnea in humans: present knowledge and future investigations. Respir Physiol Neurobiol 188:289-300. CrossRef Medline

Matsumoto H, Hanajima R, Terao Y, Ugawa Y (2013) Magnetic-motorroot stimulation: review. Clin Neurophysiol 124:1055-1067. CrossRef Medline

Matsumoto L, Hanajima R, Matsumoto H, Ohminami S, Terao Y, Tsuji S, Ugawa Y (2010) Supramaximal responses can be elicited in hand muscles by magnetic stimulation of the cervical motor roots. Brain Stimul 3:153-160. CrossRef Medline

McCrimmon DR, Smith JC, Feldman JL (1989) Involvement of excitatory amino-acids in neurotransmission of inspiratory drive to spinal respiratory motoneurons. J Neurosci 9:1910-1921. Medline

McGuire M, Liu C, Cao Y, Ling L (2008) Formation and maintenance of ventilatory long-term facilitation require NMDA but not non-NMDA receptors in awake rats. J Appl Physiol 105:942-950. CrossRef Medline

Mehiri S, Straus C, Arnulf I, Attali V, Zelter M, Derenne JP, Similowski T (2006) Responses of the diaphragm to transcranial magnetic stimulation during wake and sleep in humans. Respir Physiol Neurobiol 154:406418. CrossRef Medline

Merrill EG, Fedorko L (1984) Mono-synaptic inhibition of phrenic motoneurons - a long descending projection from Botzinger neurons. J Neurosci 4:2350-2353. Medline

Mitchell GS, Baker TL, Nanda SA, Fuller DD, Zabka AG, Hodgeman BA, Bavis RW, Mack KJ, Olson EB (2001) Invited review: Intermittent hypoxia and respiratory plasticity. J Appl Physiol 90:2466-2475. Medline

Mitchell GS, Johnson SM (2003) Plasticity in respiratory motor controlinvited review: neuroplasticity in respiratory motor control. J Appl Physiol 94:358-374. Medline

Mitchell GS, Terada J (2011) Should we standardize protocols and preparations used to study respiratory plasticity? Respir Physiol Neurobiol 177: 93-97. CrossRef Medline

Murphy K, Mier A, Adams L, Guz A (1990) Putative cerebral cortical involvement in the ventilatory response to inhaled $\mathrm{co} 2$ in conscious man. J Physiol 420:1-18. Medline

Nitsche MA, Fricke K, Henschke U, Schlitterlau A, Liebetanz D, Lang N, Henning S, Tergau F, Paulus W (2003) Pharmacological modulation of cortical excitability shifts induced by transcranial direct current stimulation in humans. J Physiol 553:293-301. CrossRef Medline

Parazzini M, Rossi E, Ferrucci R, Liorni I, Priori A, Ravazzani P (2014) Modelling the electric field and the current density generated by cerebellar transcranial DC stimulation in humans. Clin Neurophysiol 125:577-584. CrossRef Medline

Poon CS, Barahona M (2001) Titration of chaos with added noise. Proc Natl Acad Sci U S A 98:7107-7112. CrossRef Medline

Priori A, Ciocca M, Parazzini M, Vergari M, Ferrucci R (2014) Transcranial cerebellar direct current stimulation and transcutaneous spinal cord direct current stimulation as innovative tools for neuroscientists. J Physiol 592:3345-3369. CrossRef Medline

Raux M, Xie H, Similowski T, Koski L (2010) Facilitatory conditioning of the supplementary motor area in humans enhances the corticophrenic responsiveness to transcranial magnetic stimulation. J Appl Physiol 108: 39-46. CrossRef Medline

Rekling JC, Funk GD, Bayliss DA, Dong XW, Feldman JL (2000) Synaptic central of motoneuronal excitability. Physiol Rev 80:767-852. Medline

Rossini PM, Barker AT, Berardelli A, Caramia MD, Caruso G, Cracco RQ, DimitrijeviæMR, Hallett M, Katayama Y, LückingCH, Maertens de Noordhout AL, Marsden CD, Murray NMF, Rothwell JC, Swash M, Tomberg C (1994) Non-invasive electrical and magnetic stimulation of the brain, spinal cord and roots: basic principles and procedures for routine clinical application. Report of an IFCN committee. Electroencephalogr Clin Neurophysiol 91:79-92. CrossRef Medline

Rothwell JC, Day BL, Thompson PD, Kujirai T (2009) Short latency intracortical inhibition: one of the most popular tools in human motor neurophysiology. J Physiol 587:11-12. CrossRef Medline

Roulin E, Freitas US, Letellier C (2011) Working conditions for safe detection of nonlinearity and noise titration. Phys Rev E Stat Nonlin Soft Matter Phys. 83:046225. CrossRef Medline 
SaboiskyJ, Gorman RB, De Troyer A, Gandevia SC, Butler JE (2007) Differential activation among five human inspiratory motoneuron pools during tidal breathing. J Appl Physiol 102:772-780. CrossRef Medline

Schmid UD, Walker G, Hess CW, Schmid J (1990) Magnetic and electrical stimulation of cervical motor roots: technique, site and mechanisms of excitation. J Neurol Neurosurg Psychiatry 53:770-777. CrossRef Medline

Schmidt M, Demoule A, Cracco C, Gharbi A, Fiamma MN, Straus C, Duguet A, Gottfried SB, Similowski T (2010) Neurally adjusted ventilatory assist increases respiratory variability and complexity in acute respiratory failure. Anesthesiology 112:670-681. CrossRef Medline

Sharshar T, Hopkinson NS, Jonville S, Prigent H, Carlier R, Dayer MJ, Swallow EB, Lofaso F, Moxham J, Polkey MI (2004) Demonstration of a second rapidly conducting cortico-diaphragmatic pathway in humans. J Physiol 560:897-908. CrossRef Medline

Similowski T, Fleury B, Launois S, Cathala HP, Bouche P, Derenne JP (1989) Cervical magnetic stimulation: a new painless method for bilateral phrenic nerve stimulation in conscious humans. J Appl Physiol 67:13111318. Medline

Similowski T, Mehiri S, Duguet A, Attali V, Straus C, Derenne JP (1997) Comparison of magnetic and electrical phrenic nerve stimulation in assessment of phrenic nerve conduction time. J Appl Physiol 82:1190-1199. Medline

Stagg CJ, Nitsche MA (2011) Physiological basis of transcranial direct current stimulation. Neuroscientist 17:37-53. CrossRef Medline

Stein PK, Domitrovich PP, Huikuri HV, Kleiger RE (2005) Traditional and nonlinear heart rate variability are each independently associated with mortality after myocardial infarction. J Cardiovasc Electrophysiol 16:1320. CrossRef Medline

Stinear CM, Byblow WD (2004) Elevated threshold for intracortical inhibition in focal hand dystonia. Mov Disord 19:1312-1317. CrossRef Medline

Straus C, Locher C, Zelter M, Derenne JP, Similowski T (2004) Facilitation of the diaphragm response to transcranial magnetic stimulation by increases in human respiratory drive. J Appl Physiol 97:902-912. CrossRef Medline
Straus C, Samara Z, Fiamma MN, Bautin N, Ranohavimparany A, Le Coz P, Golmard JL, Darré P, Zelter M, Poon CS, Similowski T (2011) Effects of maturation and acidosis on the chaos-like complexity of the neural respiratory output in the isolated brainstem of the tadpole, Rana esculenta. Am J Physiol Regul Integr Comp Physiol 300:R1163-R1174. CrossRef Medline

Syed Z, Lin HS, Mateika JH (2013) The impact of arousal state, sex, and sleep apnea on the magnitude of progressive augmentation and ventilatory long-term facilitation. J Appl Physiol 114:52-65. CrossRef Medline

Toshev PK, Guleyupoglu B, Bikson M (2014) Informing dose design by modeling transcutaneous spinal direct current stimulation Clin Neurophysiol. Advance online publication. Retrieved April 4, 2014. doi: 10.1016/j.clinph.2014.03.022. CrossRef.

Truini A, Vergari M, Biasiotta A, La Cesa S, Gabriele M, Di Stefano G, Cambieri C, Cruccu G, Inghilleri M, Priori A (2011) Transcutaneous spinal direct current stimulation inhibits nociceptive spinal pathway conduction and increases pain tolerance in humans. Eur J Pain 15:1023-1027. CrossRef Medline

Ugawa Y, Rothwell JC, Day BL, Thompson PD, Marsden CD (1989) Magnetic stimulation over the spinal enlargements. J Neurol Neurosurg Psychiatry 52:1025-1032. CrossRef Medline

Verin E, Marie JP, Similowski T (2011) Cartography of human diaphragmatic innervation: preliminary data. Respir Physiol Neurobiol 176:6871. CrossRef Medline

Winkler T, Hering P, Straube A (2010) Spinal DC stimulation in humans modulates post-activation depression of the H-reflex depending on current polarity. Clin Neurophysiol 121:957-961. CrossRef Medline

Wolpaw JR, Carp JS (2006) Plasticity from muscle to brain. Prog Neurobiol 78:233-263. CrossRef Medline

Wysocki M, Fiamma MN, Straus C, Poon CS, Similowski T (2006) Chaotic dynamics of resting ventilatory flow in humans assessed through noise titration. Respir Physiol Neurobiol 153:54-65. CrossRef Medline 